\title{
CARACTERIZAÇÃO QUALITATIVA E QUANTITATIVA DO BAGAÇO DA CASCA DE COCO VERDE UTILIZANDO MÉTODOS TRADICIONAIS E A ESPECTROSCOPIA NO INFRAVERMELHO PRÓXIMO (NIRS).
}

\author{
R. J. A. NASCIMENTO ${ }^{1}$, A. P. P. FLORENTINO ${ }^{1}$, E. S. SANTOS ${ }^{1}$, J. A. OLIVEIRA ${ }^{1}$, G. R. \\ MACEDO $^{1}$ \\ ${ }^{1}$ Universidade Federal do Rio Grande do Norte, Departamento de Engenharia Química \\ E-mail para contato: ruthjessica@gmail.com
}

\begin{abstract}
RESUMO - O bagaço da casca de coco verde foi submetido a quatro tipos de prétratamentos: Autocatalítico, alcalino, Físico-químico com solução de $\mathrm{H}_{3} \mathrm{PO}_{4}$ a $0,2 \%$ e Físico-químico com solução de $\mathrm{H}_{2} \mathrm{SO}_{4}$ a $2 \%$. Os pré-tratamentos foram utilizados para diminuir os teores de lignina e hemicelulose do bagaço de coco verde in natura. $\mathrm{O}$ bagaço com pré-tratamento alcalino apresentou maior redução no teor de lignina, enquanto os bagaços pré-tratados com $\mathrm{H}_{3} \mathrm{PO}_{4}$ a $0,2 \%$ e com pré-tratamento autocatalítico apresentaram maior redução no teor de hemicelulose. Mudanças nos teores de lignina, hemicelulose e celulose cristalina e amorfa foram caracterizados utilizando NIRS com bons resultados. A análise dos espectros normalizados e pré-tratados com $2^{\text {a }}$ derivada possibilitou observar regiões características das estruturas do material lignocelulósico.
\end{abstract}

\section{INTRODUÇÃO}

As fontes de energia renovável vêm ao longo dos anos ganhando maior destaque na matriz energética brasileira e mundial, por serem menos danosos ao meio ambiente, apresentam-se como alternativas aos combustíveis fósseis e seus derivados (Naik et al., 2010). A biomassa lignocelulósica é uma fonte renovável de matéria-prima que pode ser utilizada na produção de combustíveis líquidos e gasosos, produtos termoquímicos e diversos outros produtos (Sanderson et al., 1996), sendo assim a biomassa lignocelulósica se apresenta como a matéria-prima mais favorável na implantação futura das chamadas biorefinarias.

Os materiais lignocelulósicos formam um recurso natural renovável e abundante em todas as regiões do nosso planeta (Aristidou e Pentillä, 2000), possuem em sua composição biopolímeros como celulose, hemicelulose e lignina. Vários tipos de biomassa podem ser utilizados para a produção de biocombustíveis, e estas são constituídas principalmente por resíduos da agricultura (Aristidou e Pentillä, 2000), e por materiais provenientes da atividade agroindustrial e florestal, tais como palhas de arroz e trigo, sabugo de milho, casca de aveia, bagaço de cana de açúcar, bagaço de arroz, aparas de Eucalipto entre outros (Rocha, M. V. P., 2010).

A celulose, a hemicelulose e a lignina presentes na biomassa lignocelulósica se associam de 


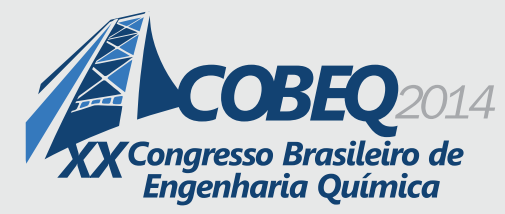

uma forma complexa e, dessa forma, definem a estrutura dos vegetais (Rocha, M. V. P., 2010). De acordo com Aristidou e Pentillä (2000) estes materiais possuem entre $25 \%$ e $60 \%$ de celulose e entre $10 \%$ e $35 \%$ de hemicelulose, sendo que a composição de celulose, hemicelulose e lignina presentes variam de acordo com a parte e espécie do vegetal, e condições ambientais (Mckendry, 2002 apud Hou \& Li, 2011).

As frações constituintes dos materiais lignocelulósicos se associam de uma maneira complexa que conferem a estes materiais alta resistência ao ataque de agentes químicos, enzimáticos e microbianos, sendo então necessária a utilização de métodos de pré-tratamento, hidrólise e deslignificação para transformar a celulose e a hemicelulose em açúcares disponíveis para a fermentação (Puri \& Pearce, 1986 apud Rocha, M. V. P., 2010, p. 32).

$\mathrm{O}$ rendimento dos processos envolvendo biomassa lignocelulósica depende fortemente da característica da matéria-prima empregada, pois mudanças na sua composição podem acarretar variações na qualidade do produto final e no rendimento do processo (Guo et. al., 2009; Sluiter et al., 2010), sendo assim, torna-se necessário a caracterização do material lignocelulósico com o intuito de manter o processo operando em condições ótimas.

O bagaço da casca de coco verde foi submetido a quatro tipos de pré-tratamentos: Autocatalítico, alcalino, Físico-químico com solução de $\mathrm{H}_{3} \mathrm{PO}_{4}$ a $0,2 \%$ e Físico-químico com solução de $\mathrm{H}_{2} \mathrm{SO}_{4}$ a $2 \%$. A estrutura do material lignocelulósico é alterada durante o pré-tratamento e os métodos de caracterização empregados para averiguar estas variações são demorados e necessitam de reagentes químicos para realizar as análises que acabam por destruir a estrutura do material. A espectroscopia no infravermelho próximo surge como uma técnica alternativa rápida, não destrutiva e com grande potencial para caracterizar de maneira qualitativa e quantitativa a biomassa lignocelulósica (Krongtaew et. al., 2010).

O objetivo básico deste trabalho foi realizar a caracterização do bagaço da casca de coco verde in natura e pré-tratado, através dos métodos convencionais e com espectroscopia no infravermelho próximo, com a finalidade de determinar as composições de celulose, hemicelulose e lignina e averiguar quais os efeitos causados pelo pré-tratamento na fibra do material lignocelulósico.

\section{MATERIAL E MÉTODOS}

\subsection{Material}

O bagaço de coco verde foi adquirido através de coleta em um ponto de venda de água de coco em Natal/RN. O material in natura apresenta a seguinte composição: 35,37\% de celulose, 23,29 $\%$ de hemicelulose, $26,29 \%$ de lignina total, $4,38 \%$ de extraíveis, $3,59 \%$ de cinzas e 7,08 \% de Umidade.

\subsection{Métodos}

Pré-tratamento do bagaço: O bagaço da casca de coco verde foi moído em um moinho de 


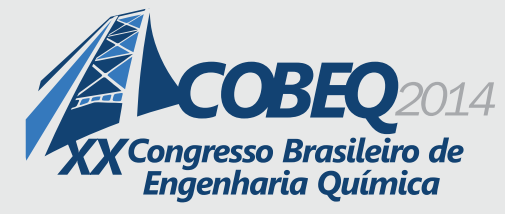

facas (Moinho tipo willey, TE-680, Tecnal) e peneirado em uma peneira de 20 mesh, para uniformizar a granulometria do material. Sendo então submetido a quatro tipos de pré-tratamento diferentes, sendo eles: tratamento autocatalítico (Carga de bagaço: $5 \% \mathrm{~m} / \mathrm{v}, 186^{\circ} \mathrm{C}, 10 \mathrm{~min}$ ), tratamento com solução de ácido fosfórico 0,2\% m/v (Carga de bagaço: $5 \% \mathrm{~m} / \mathrm{v}, 186^{\circ} \mathrm{C}, 10 \mathrm{~min}$ ), tratamento com solução de ácido sulfúrico $2 \% \mathrm{~m} / \mathrm{v}$ (Carga de bagaço: $10 \% \mathrm{~m} / \mathrm{v}, 121^{\circ} \mathrm{C}, 30 \mathrm{~min}$ ) e tratamento alcalino com solução de $\mathrm{NaOH}$ a $0,5 \% \mathrm{~m} / \mathrm{v}$ (Carga de bagaço: $10 \% \mathrm{~m} / \mathrm{v}, 121^{\circ} \mathrm{C}, 30 \mathrm{~min}$ ).

Caracterização do material lignocelulósica: Para a caracterização foi utilizado o procedimento de caracterização da NREL. Para determinação da umidade foram colocados $3 \mathrm{~g}$ de bagaço em 3 béqueres de $100 \mathrm{~mL}$, previamente tarados. O béquer é fechado com papel alumínio e levado para estufa a $100^{\circ} \mathrm{C}$ por $24 \mathrm{~h}$. Para a determinação de extraíveis, $3 \mathrm{~g}$ de bagaço foram extraídos consecutivamente em extrator tipo soxlet com os seguintes solventes: Diclorometano $\left(24 \mathrm{~h}, 50^{\circ} \mathrm{C}\right)$, Etanol/tolueno $\left(1: 2,24 \mathrm{~h}, 120^{\circ} \mathrm{C}\right)$, Etanol a $95 \%\left(24 \mathrm{~h}, 80^{\circ} \mathrm{C}\right)$ e Água $\left(24 \mathrm{~h}, 110^{\circ} \mathrm{C}\right)$. A determinação de polissacarídeos foi realizada após hidrólise ácida ( $2 \mathrm{~g}$ de bagaço, $\mathrm{H}_{2} \mathrm{SO}_{4}$ à $\left.72 \%, 45^{\circ} \mathrm{C}, 7 \mathrm{~min}\right)$. Os teores de celulose e hemicelulose dependem das concentrações de carboidrato e de ácidos orgânicos presentes no hidrolisado. Após a hidrólise, a mistura reacional é filtrada em papel filtro previamente seco e tarado. As concentrações de carboidrato e ácidos orgânicos são determinadas por cromatografia líquida de alto desempenho (CLAE). O material sólido retido no papel filtro corresponde à lignina insolúvel. $\mathrm{O}$ teor de cinzas totais é o resíduo após a ignição de $2 \mathrm{~g}$ de bagaço a $800^{\circ} \mathrm{C}$ por $2 \mathrm{~h}$. $\mathrm{O}$ teor de lignina foi determinado subtraindo os teores de celulose, hemicelulose, extraíveis, umidade e cinzas de $100 \%$ da amostra de bagaço.

Espectroscopia no infravermelho próximo (NIRS): Os espectros das amostras de bagaço foram obtidos por um espectrofotômetro Thermo-Nicolet Antaris II FT-NIR equipado com um sensor conectado ao equipamento por cabo de fibra ótica. A ponta do sensor é chanfrada, com a finalidade de evitar a reflexão difusa e possui uma janela de safira. A aquisição dos espectros pelo instrumento é gerenciado pelo Software RESULT 3 da Thermo Scientific. O equipamento utiliza um prato de cerâmica como branco. $\mathrm{O}$ sensor foi inserido nas amostras para promover a tomada dos espectros; na região de 10.000 a $4.000 \mathrm{~cm}^{-1}$ com intervalo de $8 \mathrm{~cm}^{-1}$, e cada um destes, foi obtido a partir da média de um total de 64 escaneamentos. Os espectros foram normalizados, utilizando a normalização por vetor unitário, e depois submetidos ao pré-tratamento de segunda derivada com a finalidade de melhorar a visualização das informações contidas nos espectros.

\section{RESULTADOS E DISCUSSÃO}

\subsection{Influência do pré-tratamento na composição química do bagaço da casca de coco verde}

O bagaço da casca de coco verde apresenta em sua composição alto percentual de lignina. Altos teores de lignina não são interessantes para os processos que envolvem o material lignocelulósico, principalmente o processo de produção do etanol de $2^{\mathrm{a}}$ geração, pois a lignina atua adsorvendo parte das enzimas presentes na etapa de sacarificação enzimática diminuindo o rendimento do processo (Berlin et al., 2006). Os pré-tratamentos utilizados neste estudo tiveram por objetivo reduzir os teores de hemicelulose e lignina, aumentando assim os teores de celulose na 


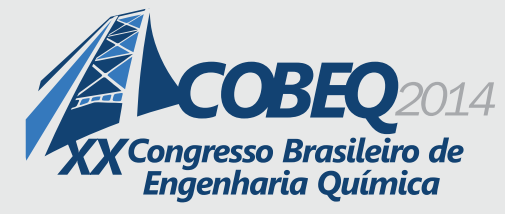

biomassa. A maior redução no teor de lignina foi observada no pré-tratamento alcalino, onde houve redução de $26,29 \%$ para $5,1 \%$ no teor de lignina e aumento proporcional na porcentagem de polissacarídeos, principalmente celulose, como mostrado na Tabela 1. Durante o pré-tratamento alcalino a lignina é removida devido à saponificação das ligações lignina-carboidrato que acontecem devido à presença de ligações éster entre resíduos de ácido ferúlico da lignina e as cadeias laterais da arabinose presente na hemicelulose (Krongtaew et al., 2010).

A hemicelulose é um polissacarídeo constituído por moléculas de diversos açúcares ligadas entre si (D-glicose, D-xilose, D-manose, D-galactose e D-galactourônico), mas não contribui de forma sensível na oferta de açúcares fermentescíveis ao processo de produção de etanol de $2^{a}$ geração, sendo assim faz-se necessário a diminuição dos teores de hemicelulose na biomassa lignocelulósica. A Tabela 1 mostra que os pré-tratamentos que causaram maior redução dos teores de hemicelulose foi o pré-tratamento autocatalítico e o pré-tratamento com $2 \%$ de ácido sulfúrico, redução de $23,29 \%$ para $13,11 \%$ e $12,51 \%$, respectivamente. O pré-tratamento com ácido sulfúrico reduziu o teor de hemicelulose, mas não teve efeito na redução do teor de lignina e devido à redução da hemicelulose presente na amostra houve o aumento proporcional nos teores de celulose e lignina. O pré-tratamento autocatalítico e os pré-tratamentos com ácido diluído agem nas camadas mais externas dos compostos amorfos da parede da célula vegetal; a hemicelulose é hidrolisada e dá origem a monômeros e oligômeros, enquanto a celulose permanece em sua maioria inalterada (Krongtaew et al., 2010).

Os pré-tratamentos utilizados também mostraram efeitos na redução dos percentuais de substâncias extraíveis; constituídos em linhas gerais por lipídeos, ceras e ácidos graxos. O prétratamento alcalino apresentou a maior redução no teor de extraíveis de 4,38\% para 0,96\%, como mostrado na Tabela 1. Todos os pré-tratamentos utilizados resultaram em menores valores de cinzas, indicando que houve extração de minerais.

Tabela 1-Composição química do bagaço da casca de coco verde in natura e pré-tratado.

\begin{tabular}{c|ccccc}
\hline \multirow{2}{*}{$\begin{array}{c}\text { Composição } \\
\text { química }\end{array}$} & Tn natura & Autocatalítico & $\mathbf{H}_{\mathbf{3}} \mathbf{P O}_{\mathbf{4}}(\mathbf{0 , 2} \% \mathbf{v} / \mathbf{v})$ & $\mathbf{H}_{\mathbf{2}} \mathbf{S O}_{\mathbf{4}}(\mathbf{2 \%} \mathbf{v} / \mathbf{v})$ & $\mathbf{N a O H}(\mathbf{0 , 5} \% \mathbf{p} / \mathbf{v})$ \\
\cline { 2 - 6 } & $35,37 \pm 0,85$ & $57,46 \pm 5,41$ & $48,98 \pm 7,23$ & $49,58 \pm 1,07$ & $57,04 \pm 3,064$ \\
Celulose & $23,29 \pm 0,11$ & $13,11 \pm 0,29$ & $22,07 \pm 3,01$ & $12,51 \pm 0,65$ & $29,32 \pm 0,34$ \\
Hemicelulose & 26,29 & 19,62 & 23,08 & 30,78 & 5,1 \\
Lignina Total & $4,38 \pm 2,58$ & $2,99 \pm 1,25$ & $1,40 \pm 0,23$ & $1,65 \pm 0,28$ & $0,96 \pm 0,06$ \\
Extraíveis & $3,59 \pm 0,47$ & $0,79 \pm 0,02$ & $0,60 \pm 0,25$ & $0,66 \pm 0,06$ & $1,49 \pm 0,48$ \\
Cinzas & $7,08 \pm 0,14$ & $6,03 \pm 0,067$ & $3,87 \pm 0,099$ & $4,82 \pm 0,35$ & $6,09 \pm 0,05$ \\
\hline Umidade & & & &
\end{tabular}

\subsection{Caracterização das estruturas químicas do bagaço por espectroscopia no infravermelho próximo (NIRS)}

Os espectros do bagaço in natura e pré-tratado foram plotados após serem normalizados e submetidos ao pré-tratamento de $2^{\mathrm{a}}$ derivada. Este tipo de processamento não influencia a posição 
original das bandas de absorção (Krongtaew et al., 2010), acentua as diferenças entre os espectros e facilita a interpretação qualitativa destes.

A Tabela 2 adaptada de Krongtaew et al., 2010 mostra as bandas de absorção na região do infravermelho próximo que são características das estruturas de lignina, celulose e hemicelulose. Algumas bandas do espectro do infravermelho próximo são característicos de polissacarídeos amorfos e de celulose semi-cristalina e cristalina.

Tabela 2 - Atribuição de bandas de absorção na espectroscopia no infravermelho próximo (Adaptado de Krongtaew et al., 2010)

\begin{tabular}{|c|c|c|}
\hline Número de onda $\left(\mathrm{cm}^{-1}\right)$ & Tipo & Grupos funcionais \\
\hline \multicolumn{3}{|l|}{ Lignina } \\
\hline 6913 & $\begin{array}{l}\text { O-H distensão e primeiro } \\
\text { sobretom }\end{array}$ & Grupos fenólicos \\
\hline 6916 & $\begin{array}{l}\text { 2xCH-distensão } \\
\text { deformação C-H }\end{array}$ & Aromáticos \\
\hline 5980 & $\begin{array}{l}\text { C-H distensão e primeiro } \\
\text { sobretom }\end{array}$ & Aromáticos \\
\hline 5800 & $\begin{array}{l}\text { C-H distensão e primeiro } \\
\text { sobretom }\end{array}$ & $\mathrm{CH}_{2}$ \\
\hline \multicolumn{3}{|l|}{ Polissacarídeos } \\
\hline $7100-6200$ & $\begin{array}{l}\text { O-H distensão e primeiro } \\
\text { sobretom }\end{array}$ & Grupos alcoólicos \\
\hline 7000 & $\begin{array}{l}\text { O-H distensão e primeiro } \\
\text { sobretom }\end{array}$ & $\begin{array}{l}\text { Polissacarídeos amorfos } \\
\text { Polissacarídeos livres de } \\
\text { grupos OH ou H } \\
\text { fracamente ligado a } \mathrm{OH}\end{array}$ \\
\hline $6970-6800$ & & $\begin{array}{ll}\text { Grupos } & \text { Oh com } \\
\text { força com de } & \text { ligação } \\
\text { intermediária } & \end{array}$ \\
\hline 6757 & $\begin{array}{l}\text { O-H distensão e primeiro } \\
\text { sobretom }\end{array}$ & Celulose cristalina \\
\hline$\sim 6722$ & $\begin{array}{l}\text { O-H distensão e primeiro } \\
\text { sobretom }\end{array}$ & Celulose semi-cristalina \\
\hline 6460 & $\begin{array}{l}\text { O-H distensão e primeiro } \\
\text { sobretom }\end{array}$ & Celulose cristalina \\
\hline 6281 & $\begin{array}{l}\text { O-H distensão e primeiro } \\
\text { sobretom }\end{array}$ & Celulose cristalina \\
\hline 5990 e 5960 & $\begin{array}{l}\mathrm{C}-\mathrm{H} \text { distensão e primeiro } \\
\text { sobretom }\end{array}$ & $\mathrm{CH}_{3}$, Acetil \\
\hline 5800 & $\begin{array}{l}\text { C-H distensão e primeiro } \\
\text { sobretom }\end{array}$ & $\begin{array}{l}\mathrm{CH} \text {, furanose ou piranose } \\
\text { devido à presença de } \\
\text { hemicelulose }\end{array}$ \\
\hline 5208 & $\begin{array}{l}\mathrm{C}-\mathrm{H} \text { distensão, } \mathrm{O}-\mathrm{H} \\
\text { dobramento }\end{array}$ & Polissacarídeos \\
\hline$\sim 4785$ & combinação de O-H & Polissacarídeos \\
\hline
\end{tabular}




\begin{tabular}{lll}
\hline 4405 & O-H e C-H distensão & Polissacarídeos \\
C295 & $\begin{array}{l}\text { Combinação de distensão } \\
\text { e dobramento de C-H }\end{array}$ & Polissacarídeos \\
\hline
\end{tabular}

A banda de absorção mais visível da lignina acontece próximo de $5980 \mathrm{~cm}^{-1}$. Nesta região ocorre a distensão e o primeiro sobretom da ligação $\mathrm{C}-\mathrm{H}$ de compostos aromáticos presentes na estrutura da lignina, como pode ser observado na Figura 1. Para número de onda igual a $5800 \mathrm{~cm}^{-1}$, podemos também observar na Figura 1, a distensão e primeiro sobretom da ligação C-H presentes na estrutura da hemicelulose.

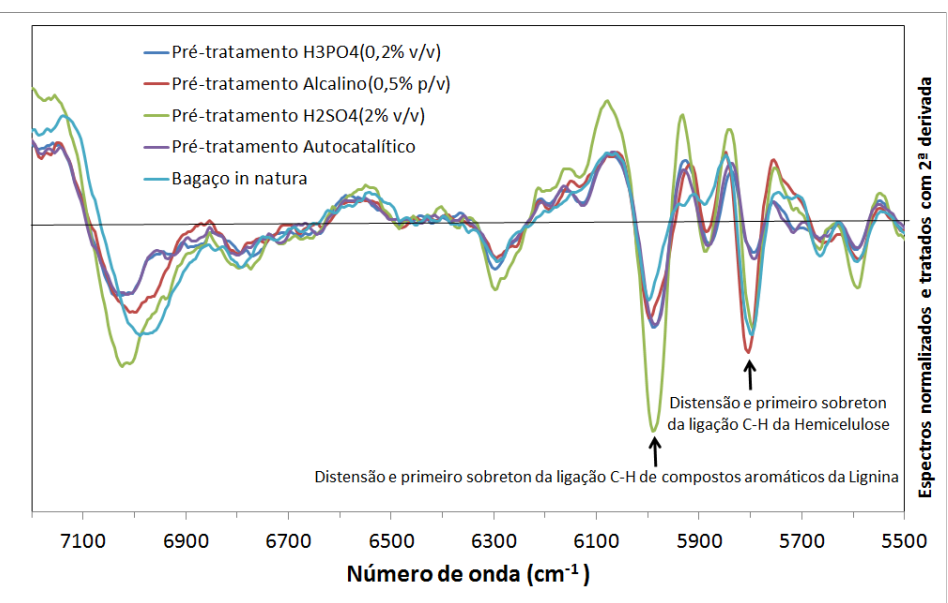

Figura 1 - Espectros do bagaço in natura e pré-tratado com atribuição de bandas de absorção para lignina e hemicelulose na região do infravermelho próximo $\left(7200 \mathrm{a} 5500 \mathrm{~cm}^{-1}\right)$.

A Figura 2 mostra os espectros normalizados e pré-tratados com $2^{\mathrm{a}}$ derivada das amostras do bagaço da casca de coco verde pré-tratado. $O$ processo de deslignificação devido à ação do prétratamento utilizado pode ser visualizado na Figura 2 através da mudança nos mínimos locais em $5980 \mathrm{~cm}^{-1}$, que diminuíram de acordo com a redução do teor de lignina em cada tipo de bagaço prétratado.

Bandas características de polissacarídeos aparecem entre 7100 e $6200 \mathrm{~cm}^{-1}$, devido à distensão e primeiro sobretom da ligação $\mathrm{O}-\mathrm{H}$ de grupos alcoólicos, e próximos a $4250 \mathrm{~cm}^{-1}$ devido à combinação da vibração e $2^{\circ}$ sobretom do grupo $\mathrm{CH}_{2}$ (Krongtaew et al., 2010). As bandas características da hemicelulose se devem ao $1^{\circ}$ sobretom da ligação C-H de grupos acetil. Piranoses e furanoses da hemicelulose absorvem fortemente, próximos a $5800 \mathrm{~cm}^{-1}$.

O mínimo local em $5800 \mathrm{~cm}^{-1}$ indica a presença de hemicelulose no material analisado. Na Figura 2 pode-se observar que a variação da amplitude deste mínimo local indica a variação no teor de hemicelulose da amostra. As amostras que apresentaram menor amplitude de mínimo local foram as amostras de bagaço com pré-tratamento autocatalítico e bagaço pré-tratado com $\mathrm{H}_{3} \mathrm{PO}_{4}(0,2 \% \mathrm{v} / \mathrm{v})$. $\mathrm{O}$ teor de hemicelulose para o bagaço com pré-tratamento autocatalítico apresentou teor de hemicelulose igual a $13,11 \%$. A amplitude do mínimo local para o bagaço pré-tratado com $\mathrm{H}_{3} \mathrm{PO}_{4}$ 


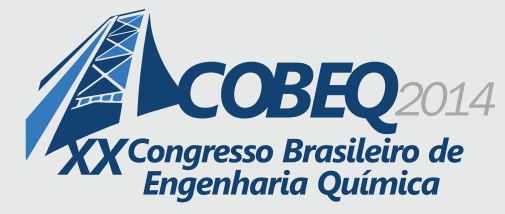

$(0,2 \% \mathrm{v} / \mathrm{v})$ foi menor que a amplitude do mínimo local para o bagaço pré-tratado com $\mathrm{H}_{2} \mathrm{SO}_{4}(2 \%$ $\mathrm{v} / \mathrm{v}$ ), contrariando os valores obtidos experimentalmente para o teor de hemicelulose, 22,07\% e $12,51 \%$, respectivamente. Isto indica a possibilidade de algum erro experimental na medida dos teores de hemicelulose, pois a amplitude do mínimo local em $5800 \mathrm{~cm}^{-1}$ está diretamente ligada à quantidade de ligações $\mathrm{C}-\mathrm{H}$ presentes, quanto maior a quantidade destas ligações maior a quantidade de hemicelulose na amostra. Observando a Figura 2 pode-se perceber que os pré-tratamentos autocatalítico, e com ácidos diluídos $\left(\mathrm{H}_{3} \mathrm{PO}_{4}(0,2 \% \mathrm{v} / \mathrm{v})\right.$ e $\mathrm{H}_{2} \mathrm{SO}_{4}(2 \% \mathrm{v} / \mathrm{v})$,) apresentaram maior redução no teor de hemicelulose, pois apresentaram menores amplitudes de mínimo local em 5800 $\mathrm{cm}^{-1}$.

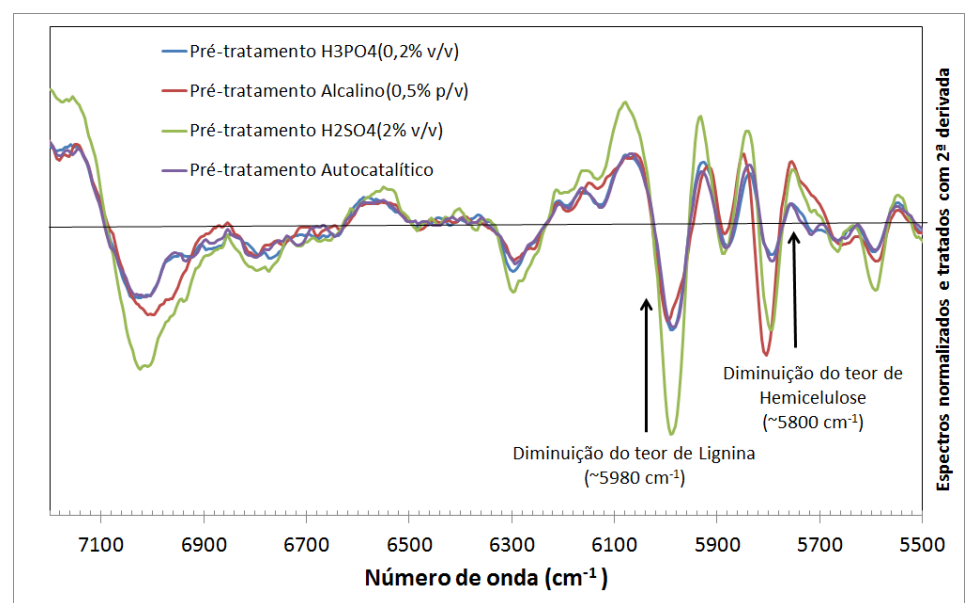

Figura 2 - Espectros das amostras de bagaço pré-tratado com atribuição de decréscimo dos teores de lignina e hemicelulose (Intervalo: 7200 a $5500 \mathrm{~cm}^{-1}$ ).

\section{CONCLUSÃO}

A espectroscopia no infravermelho próximo apresentou potencial para a análise qualitativa de materiais lignocelulósico, pois através do estudo dos espectros normalizados e pré-tratados com $2^{\mathrm{a}}$ derivada foi possível visualizar modificação na amplitude de mínimos locais que podem ser correlacionados com redução nos teores de lignina e hemicelulose. Os pré-tratamentos empregados no bagaço da casca de coco verde reduziram os teores de lignina e hemicelulose. O pré-tratamento alcalino apresentou maior redução no teor de lignina e os pré-tratamentos com ácido diluído foram mais efetivos na redução dos teores de hemicelulose.

A espectroscopia no infravermelho próximo é uma ferramenta com potencial para caracterizar qualitativamente materiais lignocelulósicos, averiguando variações nos teores de lignina e hemicelulose e pode vir a ser utilizada na seleção da matéria-prima lignocelulósica para processos com este tipo de material.

\section{REFERÊNCIAS}

Aristidou, A.; Pentillä, M. Metabolic engineering applications to renewable resource utilization. 


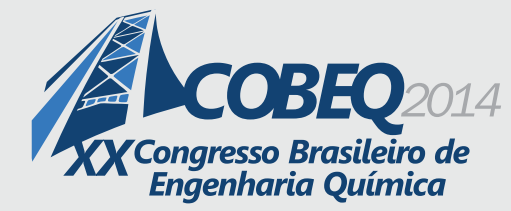

Biochem. Eng. J.,v.11, p. 187 - 198, 2000.

Berlin A, Balakshin M, Gilkes N, Kadla J. Inhibition of cellulase, xylanase and $\beta$-glucosidase activities by softwood lignin preparations. J. Biotechnol., v.125, p. 198-209, 2006.

Guo, G., Chen, W., Men, L. Hwang, W. Characterization of enzymatic saccharification for acidpretreated lignocellulosic materials with diferente lignina composition. Enzyme Microb. Technol., v. 45, p. 80-87, 2009.

Hou, S., Li, L. Rapid Characterization of woody biomass digestibility and chemical composition usinf near-infrared spectroscopy. J. Integr. Plant Biol., v. 53(2), p. 166-175, 2011.

Krongtaew, C., Messner, K., Ters, T., Fackler, K. Characterization of key parameters for biotechnological lidnocellulose conversion assessed by FT-NIR spectroscopy. Part I: Qualitative analysis of pretreated straw. BioResources., v. 5(4), p. 2063-2080, 2010.

Naik, S., Goud, V. V., Rout, P. K., Jacobson, K. Dalai, A. K. Characterization of canadian biomass for alternative renewable biofuel. Renew. Energ., v. 35, p. 1624-1631, 2010.

Rocha, M. V. P. Produção de bioetanol a partir de pedúnculo de caju (Anacardium occidentale L.) por fermentação submersa. 2010. 190f. Tese (Doutorado em Engenharia Química) - Centro de Tecnologia, Departamento de Engenharia Química, Programa de Pós-Graduação em Engenharia Química, Universidade Federal do RioGrande do Norte, Natal.

Sluiter, J. B., Ruiz, R. O., Scarlata, C. J., Sluiter, A. D. Compositional Analysis of Lignocellulosic Feedstocks.1. Review and Description of Methods. J. Agric. Food Chem., v. 58, p. 9043-9053, 2010.

Sanderson M.A., Agblevor F., Collins M., Johnson D.K. Compositional analysis of biomass feed stocks by near infrared reflectance spectroscopy. Biomass Bioeng., v. 11, p. 365-70, 1996. 